\title{
GIS and Data Management of Champedak and Local Wisdom of Champedak Gardener, Satun Province
}

\author{
Aumnat Tongkaw ${ }^{1}$ and Sasalak Tongkaw ${ }^{2}$ \\ 1,2 Faculty of Science and Technology, Songkhla Rajabhat University, 160 Kanjanawanit Road, \\ Moung Songkhla, Songkhla, 90000, Thailand
}

\begin{abstract}
This research is a GIS application for data management of the Champedak local wisdom. Champedak is a kind of plant, farmed in Satun Province. This research is an application development which practices computer innovation technology to help proceed, develop ideas and improve the ecological operations relating to the resources in the area. The application is for collecting Champedak information associated with the sustainable genetic conservation of Champedak plants. This will assist to record primary information, including the location of the Champedak tree and the figure of Champedak trees in each particular garden. A website was designed as a research tool which can display, search, and update the Champedak information. The case study of this research is in Khuan Done District, Satun Province, a service area of Songkhla Rajabhat University. The assessment results of the four satisfaction aspects are the installation process and the understanding of the application, the overview of the application, the aspects the user interface, and the usability. The average is at the highest level. Also, this research is a guideline for the conservation of genetically engineered plants and other plants with GIS in the future.
\end{abstract}

\section{Introduction}

This research highlights database development and management of information and local wisdom of the Champedak gardeners in Satun Province. Overall, it is a research and development that brings innovations, computer technology to help proceed, develop ideas and improve the ecological operations concerning various resources. The information presented is both quantitative and qualitative. The researcher requires developing an application to accumulate the necessary information needed for the research and plans the user satisfaction survey after the innovation. The data will be analyzed through statistical analysis, with the data collection from experts such as garden owners, and students participating in self-storage.

The system can store the information, resources, and wisdom of the local gardeners. These resources are located in different provinces. On issues, It can be stored even in remote locations or in any province. Also, the system can display detailed information and can process information on Champedak tree. It can also be classified to each particular type and displayed on Google map. The system itself can be presented both online and offline. 
Moreover, the database administrator can edit the data if any part of the data is incomplete or need to be updated. The System function is collecting and displaying in realtime. If there is input, the data regarding the location of the tree will be listed in the database. The application itself automatically creates coordinates by the location of which the editor determines. The security of the data is stored in a database with high data privacy. The data collected and can be used by authorized resource owners and administrators, or administrators alone. General users may only have access to some snapshots pictures of the resources, such as where the Champedak trees are located. To illustrate, a 100-year-old Champedak tree in Kuan Don district, Satun can be located using this system.

Geographic Information System or GIS is a beneficial alternative for mapping and pinpoint locations. There is much use of GIS regarding natural resource management including the designation of forest areas and surface or underground water sources. The geology of rocks and minerals, Coastal and climatic conditions can be represented in the field of spatial data management showing as images. Maps are used accompanied with descriptive or database data. The combination of both types of data, allow users to display both types of information simultaneously.

It is often a narrative that information in most organizations holds a large amount of information, it is quite difficult to manage data. Some of the updates cannot be made immediately. Consequently, the data is not up to date. Also, it may be difficult to edit because most of the information is in the form of a do9ocument or file which Data duplication may occur. As a result, the data management is not very useful.

The research was developed on map web application service called LongdoMap, generally, a map of Thailand. This serves as a web application for general users and developers.[1]

Research related to Geographic Information System is, in practice, the GIS application on Elementary School Students of Satun Educational Service Area Office by Marsh Technology, which includes a web application format to facilitate searching for the student and school information. Student home locations on Google Maps are set in the form of placemarks using the Google Map API and KML. The system shows the boundaries of districts, roads, and waterways to support executive decisions, including student tracking and student funding. [2]

The Development of the irrigation system by the Irrigation Bureau in Thailand supported uses the same type of system to assist decision making on monitoring and implementation irrigation construction. The case study of the Irrigation Office of the Provincial Irrigation Office 16 can be seen using a similar type of system; this included the Royal Projects and the prototype of irrigation buildings. Researchers used symbols in various forms to represent irrigation buildings such as dams, floodgates, etc. [3]

The Geographic Information System Research of King Mongkut's Institute of Technology North can utilize the information 1. to help manage the site 2. to benefit the official contact 3. to present information about the location [4], The Geographic Information System based on the student dorm close to King Mongkut's University of Technology Thonburi implement GIS systems to help new students to locate dorms suitable for them [5], GIS Applications to identify hazardous information on highways in Thailand, Nakhon Pathom Province, Research on Application of Geographic Information System to determine the area Suitable for growing eucalyptus [6], Survey Research Ability to access public transport in the urban areas of the disabled. Implementation of Geographic Information System to provides public transport for the underprivileged. [20] research on the development of geographic information systems programs for the development of 
educational programs and Irrigation management, [7] which often use ArcView programs in with the assignment. [4]-[8]

This research has followed the design of the GIS application for disabled people which the system is classified into two units, the web-based site, which could show the coordinates and accumulated data of disabled people and all are displayed on Google map; and the android site. [9] The system can be linked to Google API to display the applications on both Android and the website.

This research used GIS technology for data management of local information and local wisdom of Champedak gardeners, Satun Province. Overall, it was a research and development that brings innovation, computer technology aid process, develop a database management system and improves the ecological operations of resources in various areas.

\section{Methods}

This research used a mixed method to conduct the research questions that involves collecting, analyzing and integrating quantitative and qualitative research.

By mixing both quantitative and qualitative research and data, the researcher gains in breadth and depth of understanding and collaboration, while setting up the processes of using each approach consequently. One of the most advantageous characteristics of conducting mixed methods is the use of several qualitative data sources to examine the same phenomenon, in this case, is to design and implement the Champedak information system. Triangulation allows one to identify each particular aspect of a phenomenon more efficiently by approaching it from different perspective points using both different methods and techniques. Successful mix method technique requires careful analysis of the type of information provided by each method, including its strengths and weaknesses.

This research used a qualitative method following by quantitative method. The Qualitative method in information systems contains the steps as follows: a broad overview of research methods in the field of research, limiting research framework and identifying research issues, studying theories, concepts and related research, selecting the appropriate research method, selecting the appropriate data type for research methodology, selecting a storage method, choosing the right tools for research, identifying where the data comes from and when it came from, ethical considerating data collection, accuracy and consistency, collecting data, data analysis, conclusions and discussion. However, this research cites the mixed methodology. Therefore, the results of quantitative data analysis can detailed discussions on the analysis and design of information systems. Linking to qualitative data analysis using a multivariate conceptual framework.[10]

This research developed an application to collect the Champedak information and collected a user satisfaction survey after they used the application. The research also provided statistical analysis with data collection experts such as garden owners, types, and other details. The system can store information, resources, and wisdom of local gardeners. These resources which located in different area of Stun province were collected and stored in remote locations accessed by internet. Besides, the system will display detailed information. It will show the amount and categorized Champedak data on Google maps. The system can be displayed both online and offline. Editing the data if any part of the data is corrected. Other information will also change. Real-time operation of the system and the recording of location coordinates of resources. Data recorders do not need to know the various coordinate systems. The system automatically creates coordinates by taking the location of the recorder determines the location. For the security of information, the information of the resource is stored in a database with high data security without permission to access in any private information such as telephone number. Some information can be authorized by administrators with permission of the owner and general 
system users may access some snapshots or only by the type of resources, such as types and some pictures and the location of the Champedak trees in Kuan Don district, Satun province.

Currently, mapping records on the computer are in the form of digital map data. The production of this map is as follows. There are three basic needs for education: study space, value or displayed information and location. Map production is divided into 3 ways according to the source: 1) production of field surveyors by placing evidence pins on the ground, use as a master or a map structure, then down to details to produce a striped map; 2) produced from GPS survey data, which can produce current lineage maps; and 3) production of image data, such as image data from remote sensing and sweep data, which can produce both line map and pictorial map.

\subsection{System Design}

This research used GPS technology with mobile phone to collect information of latitudes, longitudes. The

\subsubsection{JavaScript}

JavaScript is a computer language for programming on the Internet. Java is a JavaScript object-oriented scripting language also known as "scripts" in which to build and develop a website in combination with HTML to make the site look animated. Can be more responsive to users. The way it works in nature. "Interpret" or "Object OrientedProgramming". Design and development of Internet applications. HTML authors can work cross-platform. It works with both HTML and Java languages on both the client side and the server side.

\subsubsection{JSON}

JSON (JavaScript Object Notation) or javascript object notation. It is a format for exchanging computer data. The JSON format is in plain text (Plain text) that is common to all human beings. And computer programs can read understandable.

The standard format for JSON is RFC 4627. Internet media type is Application / JSON. Moreover, there is a file extension: JSON.

JSON is commonly used in web applications, especially AJAX. JSON is an alternative format for sending data. In addition to XML, which was commonly used, the reason why JSON has become popular is that it is more compact and easier to understand than XML.

The structure of the JSON format is based on the javascript relationship but is not perceived as a programming language. However, it is seen as a language in the exchange of information. Currently, there are libraries of other programming languages that process data in many JSON formats.

Table 1. Framework Design

\begin{tabular}{|c|c|}
\hline \multicolumn{2}{|c|}{ Champedak API Server } \\
PHP REST API (Laravel Framework) \\
\hline Mobile & Web Frontend \\
Application & AngularJS \\
\hline \multicolumn{2}{|c|}{ MySQL } \\
\hline
\end{tabular}


The system is made up of two parts, a mobile application, and a web frontend. Both use the same database, MySQL, and all of them are linked together by using the API server which is called PHP REST API (Laravel Framework) see Table 1.

\subsubsection{ER Diagram}

The ER Diagram design and compiled by using MySQL Workbench, a unified visual tool for database architects, developers, and DBAs. The database used in both frontend and backend of the system.

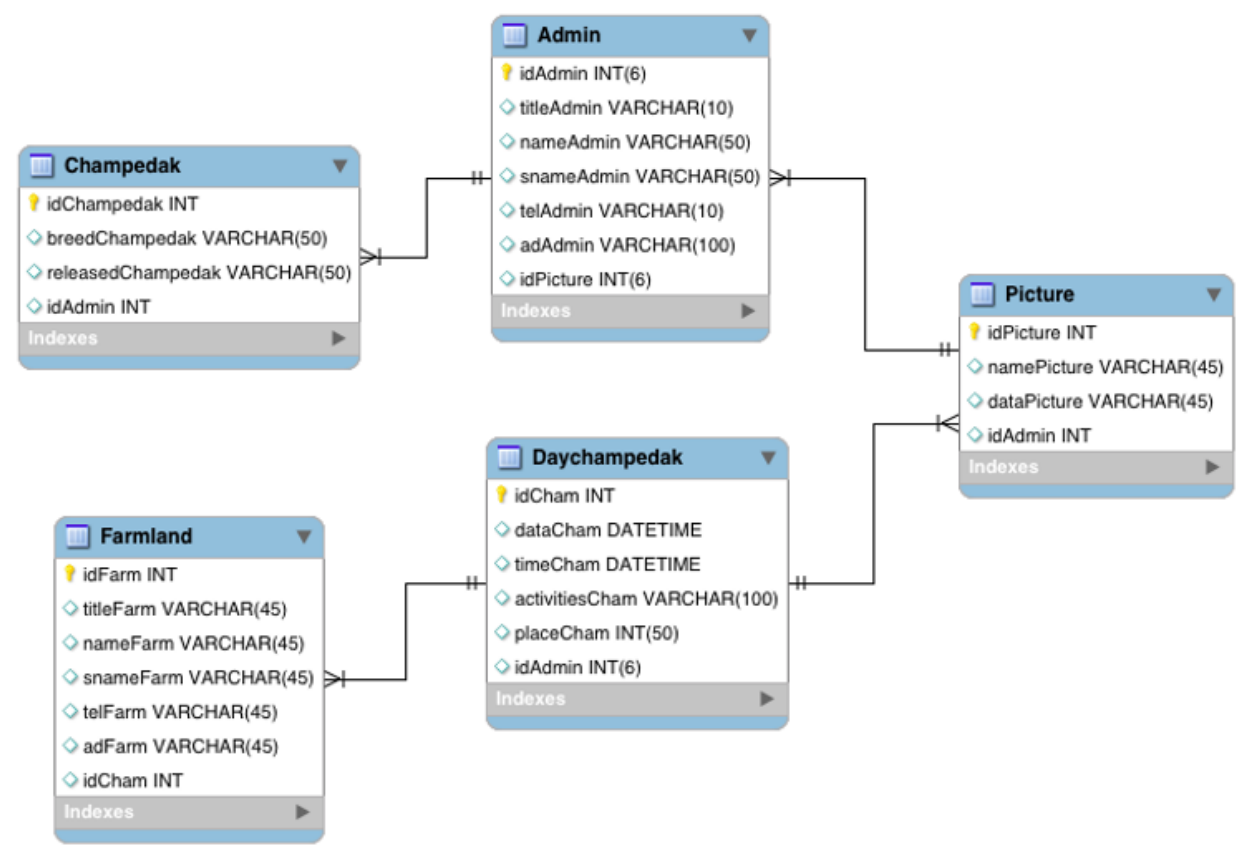

Fig. 1. ER Diagram

\subsection{System Analysis}

The system developer has made inquiries and collected information about the needs of the new system from the staff of Khuan Don District, Satun Province including 1) manage information; 2) manage longitude-latitude coordinates; 3) find a route; 4) address the location.

\subsubsection{Main Process}

Champedak management system consists of three primary systems.

1.1 Frontend system is a system where information is coordinated, the location of fruit trees are interested. The development of this system is the positioning of the rootstocks. Show on the map to know that. Where are the fruit trees located in Thailand? Also in the coordinates shown, you can also select more detailed information such as what species. What is the unique shape? Moreover, there is information of the farmer's own that can be viewed. 
1.2 Backend management system is a system for managing the backyard information of the orchard system. Within the system are composed of the System user management system including management of system permissions in various parts. Farmer Information Management System Farmer's information management system Coordinate system of the location of fruits of interest and map system

1.3 Champedak information management system on a mobile application is a system for farmers, including those who are interested. To use to record garden information. Moreover, coordinates the location of the fruit tree. Early detail Pictures and more For faster, more accurate data collection.

Geographical Information System Analysis: A case study of Khuan Don District, Satun Province, will examine the types of applications that farmers require and analyze their data needs. Problems that arise

To write a flowchart, use the symbol to write a flow diagram. Use the symbolic representation of the system function. The symbols are connected to represent the continuity of the data. Moreover, processing in a logical way. Each step of the process requires data input and output, and the direction of the arrow is an indicator of data input or output. The flowchart shows the relationship between the processes and the data.

- Where does the information come from?

- Where to go?

- Where is the data stored?

- What happened to the information on the way?

\subsubsection{System process}

From the topic of system requirements analysis. This is the demand of the system users. Two main processes can be analyzed:

1.1 Access to the system Access to the system of farmers. The administrator can manage all the system. Farmers can access only.

1.2 System Information Management Is a system information management The details are as follows

1.2.1 It is information about the farmer's history and farmer's garden information. You can add, delete, edit and find the path to the park.

1.2.2 Manage image data There is information about the farmers' photos in each of the surveyed gardens.

1.2.3 Manage location information It is information about the location of the park in Khuan Don district, it can be added, deleted, modified and searchable.

1.2.4 It is a farmer's information in Kuan Don District, Satun Province.

1.2.5 Is a day job There will be a celebration of the day. Can add, delete, modify.

\subsection{Development}

\subsubsection{Coding}

Geographical Information System Application: A case study of Kuan Don District, Satun Province, developed using Java. There is a database management system with MySQL. To store the database

Web frontend used AngularJS which connecting to Champedak API server. The Champedak API server used PHP rest API which used the laravel framework. Champedak database stored at MySQL database. The example of REST API shown in Table 2. 
Table 2. Sample code for showing details on Google Map API

var app = angular.module('myApp', ['ngMap']);

app.controller('mapController', function(\$http, \$timeout, StreetView, NgMap,\$scope) \{

var $\mathrm{vm}=$ this;

\$http.get('...../backend/public/jumpada_species').then(function(resp) \{

\$scope.jumpada_species = resp.data;

//Sscope.jumpada_species $=$ JSON.stringify(resp.data);

\}, function(err) \{ console.log('err', err)\});

NgMap.getMap().then(function(evtMap) \{

map $=$ evtMap;

vm.map = map;

vm.locations $=\{\}$;

\$http.get('../../backend/public/jumpada_param/'+sessionStorage.getItem('param')).then(function(resp) \{

vm.locations $=$ resp.data;

\} , function(err) \{ console.log('err', err)\});

vm.showLocation $=$ function $(e v t$, locationId $)\{$

vm.location $=$ vm.locations[locationId];

\}

vm.map.showInfoWindow('jumpada', this);

$/ *$

vm. mouseover $=$ function ()\{

console. $\log ($ 'mouseover');

\}$; * /$

\});

\section{Results and Discussions}

\subsection{Frontend}

Frontend system used to display the coordinates of the Champedak tree which can be reached at http://champedak.skru.ac.th/map/app/ 


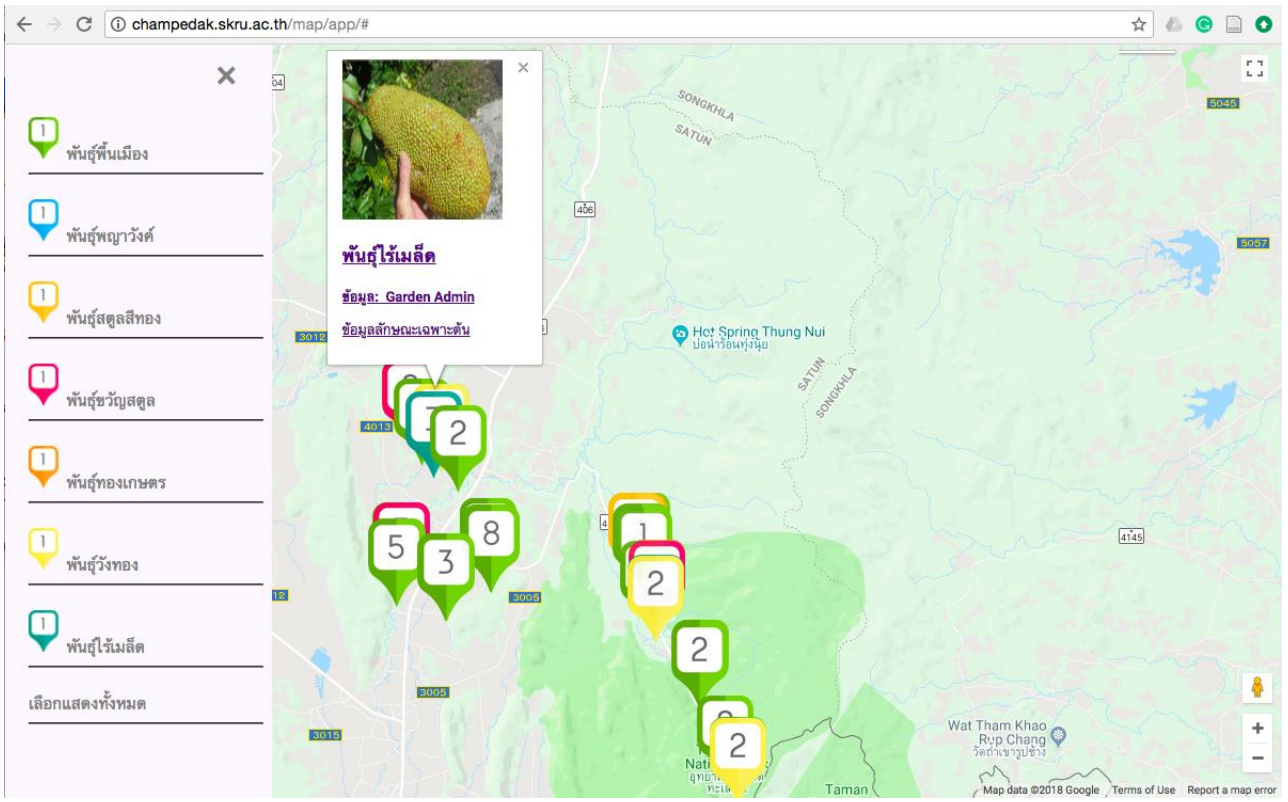

Fig. 1. Front End interface on web-based service

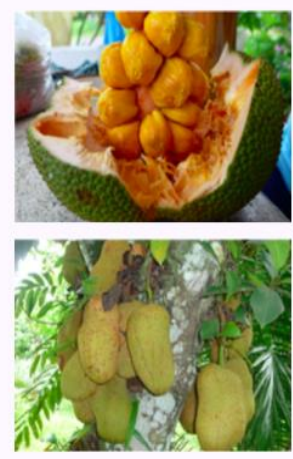

ซื่อพันธุ์ : พันธุ์สตูลสีทอง

ลักษณะทั่วไป :

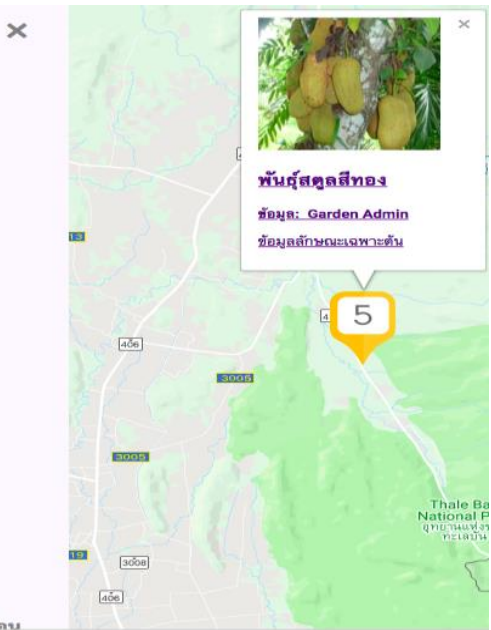

Fig. 2. Front End interface on web-based service of Champadak detail

\subsection{Backend}

Fig. 3. shows Champedak information management system - Backend. Access to the information management system required a login page. The system in this section is an administrative task, such as user data management. Farmer information, gardening information and location coordinates of Champedak trees. 


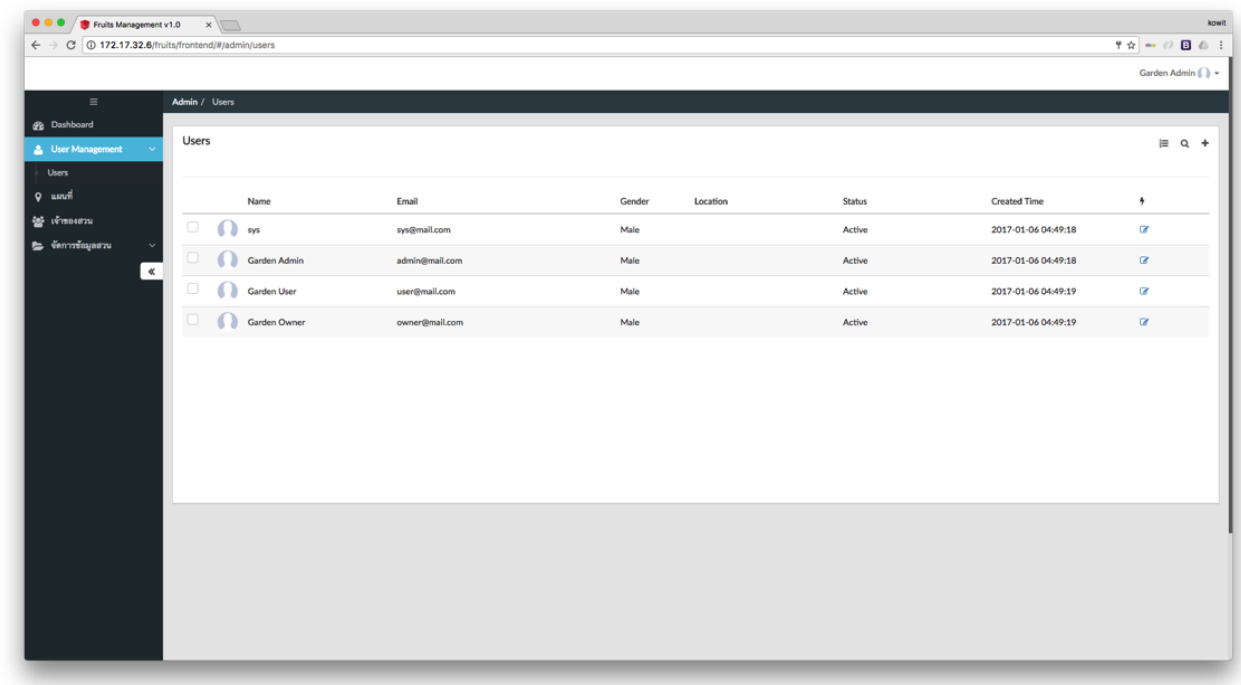

Fig. 3. The web-based backend of a Champedak information management system

\subsection{Mobile Application}

Fig. 4. Shows Champedak mobile application for collecting the data of Champedak tree.
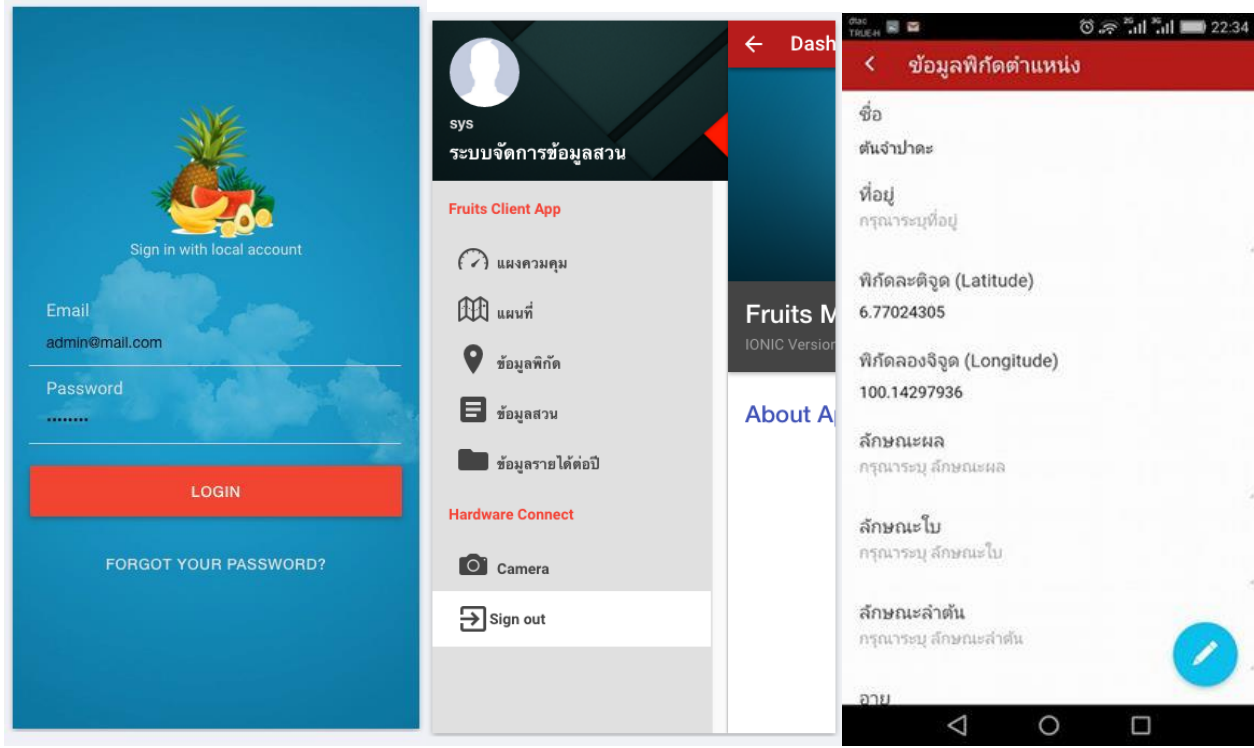

Fig. 4. The web-based backend of the Champedak information management system

The results of quantitative research in four areas.

Part 1. Installation process and application usage insight. 
Based on installation satisfaction and application insight, it is evident that the application installation process is simple and appropriate and those general users can learn and use it. Quickly Satisfaction was at the highest level. The understanding and application of the application are swift.

Part 2. Overview of the application.

Based on the overall satisfaction of the application, the satisfaction of the program Can be used and understand quickly. Also, applications. Can be displayed correctly. At the highest level, users are satisfied with their interest in the application. So the level of application is very high.

Part 3. The form and image.

The user satisfaction of the application. Style and image. Font size Within the application. Appropriate The format of the font within the application. The color of the text within the three applications is at the highest level.

\section{Part 4. Usage}

The user satisfaction of the application. The application can work properly. Users are satisfied with the application and can easily access the data. The user is satisfied. The speed of response in the application. The application is beneficial to all three aspects at the highest level.

Table 3. Satisfied Results

\begin{tabular}{|c|l|c|c|}
\hline No. & \multicolumn{1}{|c|}{ Details } & Average & Satisfied \\
\hline 1 & $\begin{array}{l}\text { The process of installing the application is appropriate and } \\
\text { straightforward. }\end{array}$ & 4.56 & Highest \\
\hline 2 & You can understand and use the application quickly & 4.28 & High \\
\hline 3 & You think that the general user can learn and use quickly & 4.53 & Highest \\
\hline 4 & $\begin{array}{l}\text { The size of the font within the application. Appropriate } \\
\text { How much? }\end{array}$ & 4.63 & Highest \\
\hline 5 & $\begin{array}{l}\text { The format of the font within the application. How very } \\
\text { suitable. }\end{array}$ & 4.66 & Highest \\
\hline 6 & Character colors within the application. How very suitable. & 4.63 & Highest \\
\hline 7 & $\begin{array}{l}\text { The size of the font within the application. Appropriate } \\
\text { How much? }\end{array}$ & 4.63 & Highest \\
\hline 8 & $\begin{array}{l}\text { The format of the font within the application. How very } \\
\text { suitable. }\end{array}$ & 4.66 & Highest \\
\hline 9 & Character colors within the application. How very suitable. & 4.63 & Highest \\
\hline 10 & The application can work correctly. & 4.69 & Highest \\
\hline 11 & $\begin{array}{l}\text { User satisfaction in the application can facilitate access to } \\
\text { data. }\end{array}$ & 4.72 & Highest \\
\hline 12 & $\begin{array}{l}\text { The user is satisfied with the speed of response of the } \\
\text { application. }\end{array}$ & 4.66 & Highest \\
\hline 13 & The application is useful. & 4.69 & Highest \\
\hline 14 & Overall, you are satisfied with the application. & Highest \\
\hline
\end{tabular}




\section{Conclusion}

Research, database development, and management of information and local wisdom of the gardeners, Satun Province. Overall, it is a research and development that brings innovations and computer technology helps to process and develop ideas.

Moreover, improve the ecological operations concerning various resources. The information presented is both quantitative and qualitative. The researcher needs to develop an application to collect the necessary information needed for the research. Also, plan the user satisfaction survey after the innovation. The data will be analyzed through statistical analysis. With data collection experts such as park owners, students participate in selfstorage. The system can store the information, resources, and wisdom of the local gardeners. These resources are located in different provinces. On issues, It can be stored even in remote locations or in any province. Besides, the system will display detailed information. So can process information about resources. It can be classified on Google map. The system can be displayed both online and offline. Editing the data if any part of the data. The other part will also change. System performance is instantaneous and location data recording of the resource base. Data recorders do not need to know about coordinate systems. Also, no need to know yourself what's on the map because the system automatically creates coordinates by the location of the recorder determines the location. The security of the data is stored in a database with high data privacy. Personal Only authorized resource owners, administrators, or administrators.

Moreover, general system users may access some snapshots. Alternatively, by the type of resources available, such as where the races are located. Where are the 100 years old in Kuan Don district, Satun.

This research supports the research methodology. This research is a research-based, mixed-method research project that presents quantitative data. Also, the same quality in the same issue. The results are clear on the issues discussed in the previous section. The conceptual framework of quantitative and qualitative data analysis is again a framework for developing applications for other data storage. Together with geographic information system The similarity.

The case study studied in this study is specific to the area of Khuan Don District. However, the proposed conceptual framework for this research can be applied to the collection of other genetic conservation data but must be in a similar context, such as the storage of perennial plants. Also, This may be a guideline for further research in the future.

This research is mixed-use research. It uses both qualitative and quantitative data. The information was gathered from stakeholders. Alternatively, system users. The data analysis was done with caution.

Based on the belief that the information obtained, the information provided by the actual data. However, the limitation may be: Data can only be stored for a period. Students are only allowed to collect some information. The number of plants in each garden is substantial. Gardeners can not tell how many, therefore, the numbers may be inaccurate. However, the coordinates of the park are displayed correctly in reliable computer systems.

Also, this research may be further developed by modifying other conservation species. This may lead to different conclusions and re-analyze the results to improve the database. Also, most useful in the future. 


\section{References}

1. W. Ampornaramwet and P. Keatsewe, 'LONGDO Map', 2008. [Online]. Available: https://map.longdo.com/. [Accessed: 25-Mar-2018].

2. W. Klinlamai, S. Wanitchayobon, and L. Prechawerakul, 'Geographic Information Systems for School/Students, Office of Student Service Area Satun', in National Conference of GISTDA 2009, (2009).

3 K. Rakkul and S. Wanitchayobon, 'Geographical for irrigation buildings by using Google Maps', in The 9th National Conference on Computing and Information Technology (NCCIT 2012), (2013).

4. U. Narumon and P. Srichaiton, 'Geographic Information System of King Mongkut's Institute of Technology North Bangkok.', King Mongkut's Institute of Technology North Bangkok., (2002).

5. T. Lapitchayangkul, 'Geographic Information System of Student Dormitory around the King Mongkut's University of Technology Thonburi', King Mongkut's University of Technology Thonburi.

6. K. Boontermkittiya, K. Khawmeche, S. Koonpinit, and S. Durongdech, 'Application of geographic information systems to determine suitable areas for eucalyptus plantation. Nakhon Phanom Province', Inf. Technol. J., pp. 150-154, (1999).

7. P. Chonkeeree, 'The development of geographic information System Program for Water Allocation Planning', Kasetsart University, (2007).

8. V. Cañal-Fernández and M. Hernández Muñiz, 'An exploratory analysis of disabled people accessibility to urban public transport: the use of Geographical Information Systems', Investig. Reg. - J. Reg. Res., no. 30, pp. 79-101, (2014).

9. S. Tongkaw, 'GIS Application Management for Disabled People', IOP Conf. Ser. Mater. Sci. Eng., vol. 226, no. 1, p. 012112, (2017).

10. David E. Avison and A. Trevor Wood-Harper, 'Information Systems Development Research: An Exploration of Ideas in Practice', Comput. J., vol. 34, pp. 98-112, Feb. (1991). 